\title{
BMJ Open Seroprevalence of antibodies against varicella zoster virus and rubella virus among newly recruited expatriate healthcare workers: a cross-sectional study
}

Ibrahim Shady

To cite: Shady I.

Seroprevalence of antibodies against varicella zoster virus and rubella virus among newly recruited expatriate healthcare workers: a crosssectional study. BMJ Open 2018;8:e019339. doi:10.1136/ bmjopen-2017-019339

- Prepublication history for this paper is available online. To view these files, please visit the journal online (http://dx.doi org/10.1136/bmjopen-2017019339).

Received 31 August 2017 Revised 5 December 2017 Accepted 14 February 2018
Check for updates

Community Medicine and Public Health Department, Faculty of Medicine, Mansoura University, Mansoura, Egypt

Correspondence to

Dr Ibrahim Shady;

ebrshady@hotmail.com

\section{ABSTRACT}

Objectives To assess the state of immunity to varicella zoster virus (VZV) and rubella virus (RV) among newly recruited healthcare workers (HCWs) in Kuwait before they begin work, and to determine whether there are differences in the prevalence of seronegativity according to nationality, gender, age group and occupation group. Setting This cross-sectional study involved analysis of blood samples from workers newly recruited to the Kuwaiti healthcare system.

Participants All new non- national HCWs recruited during the study period $(n=1540)$.

Intervention Enzyme-linked immunoassays for VZVspecific and RV-specific IgG were performed.

Results Among HCWs, $81.9 \%$ and $93.5 \%$ were immune to VZV and RV, respectively. Male seronegativity was higher than that of females for both viruses. Regarding VZV, the majority of seronegative individuals were Indians $(23.5 \%)$, followed by Somalis (12.5), Filipinos (6.5) and Egyptians (5.4\%); the between-group differences were significant for all groups. The age groups $20-30$ and $30-40$ years were most likely to be seronegative, with prevalences of $18.2 \%$ and $18.9 \%$, respectively. VZV seronegativity was most common among nurses $(21.1 \%)$ and least common among physicians (9.2\%), and the difference was significant. In addition, RV seronegativity was most frequent among Somalis (12.5\%) and lowest among Indians (5.3\%); other nationalities (Egyptian, Filipino and others) ranged between $9.1 \%$ and $9.6 \%$. Seronegative individuals were most frequently in the younger age group ( $<20$ years old) (17.5\%), followed by the $>40$ years old group $(10.4 \%)$. RV seronegativity was highest among nurses $(6.9 \%)$ and lowest among physicians (5.2\%).

Conclusion The prevalence of seronegativity is highest among Indians for VZV and Somalis for RV, and HCWs aged 20-40 years for VZV and $<20$ years for RV. For both viruses, the seronegativity rate was highest for male HCWs, and for nurses compared with other HCWs, with physicians having the lowest prevalence of both viruses.

\section{INTRODUCTION}

Varicella (chickenpox) and herpes zoster (shingles) are caused by varicella zoster virus
Strengths and limitations of this study

- The inability to project results of the current study for other areas than Arabian gulf as they share the same circumstances. Morever, small sample size as regard the study duration because it depended on how many expatriate healthcare workers (HCWs) were recruited or needed during the study period.

- The lack of collection of data/samples from Kuwaiti national HCWs as well as expatriates and the lack of collection of vaccination data for all HCWs.

- The equivocal enzyme-linked immunoassay results were considered negative, and we were unable to obtain new blood samples from these HCWs for retesting.

- We were dealing with HCWs who, after the objectives and importance of this study were explained to them, understood and cooperated during their routine examination, which is required as a prerequisite to work and reside in Kuwait.

- The study encountered some difficulties with language barriers because of the inclusion of HCWs with multiple nationalities; however, these were overcome with the help of colleagues of the same nationalities, where possible, or by knowledge of their language or use of English as a common language.

(VZV), while rubella (German measles) is caused by the rubella virus (RV). These are all transmissible vaccine-preventable diseases that can spread via contact with contaminated sources and importantly can be transmitted via the airborne route. ${ }^{1}$

VZV infection is considered a self-limiting disease in schoolchildren and younger children; however, in pregnant women, newborns, and immunocompromised and elderly individuals, VZV infection can lead to serious complications, including congenital anomalies or stillbirth, acute cerebellar ataxia, encephalitis and varicella pneumonia. 
In addition, while RV generally causes mild symptoms in children, under certain circumstances, it can lead to serious disease in pregnant women. During the first trimester of gestation, RV can pass through the placenta and cause intrauterine infection and congenital rubella syndrome. ${ }^{2-7}$

Healthcare workers (HCWs) are important sources of VZV and RV transmission and spread, because they frequently deal with pregnant women, newborns, immunocompromised patients and elderly individuals, which puts them at greater risk of being exposed to and acquiring VZV and RV. Outbreaks of these diseases have occurred in the community and in hospital settings (nosocomial infections). ${ }^{8}$

HCWs are defined as all people engaged in actions whose primary intent is to enhance health. They could potentially be exposed to infected patients and/or infectious materials, including body substances and contaminated medical supplies, surfaces or air. HCWs include (but are not limited to) health service providers (health professionals except nursing, nurses and midwifery professionals, modern health associate professionals except nursing, nursing and midwifery associate professionals, health technicians, emergency medical service personnel, dental personnel, pharmacists, laboratory personnel and autopsy personnel) and health management and support personnel (computing professionals, social science and related professionals, administrative associate professionals, secretaries and keyboard operating clerks, security, maintenance, administrative and billing staff, and volunteers). ${ }^{8}$

HCWs come to work in Kuwait from many countries, particularly low/middle-income countries where these diseases may be endemic. The main HCWs in Kuwait consist of physicians (almost $60 \%$ of whom are non-Kuwaitis), nurses (approximately $80 \%$ of whom are non-Kuwaitis), technicians (about $40 \%$ of whom are non-Kuwaitis) and other support staff (30\%-35\% of whom are non-Kuwaitis) ${ }^{9}$

A very important step in the prevention of VZV and RV outbreaks is to gather information on the state of immunity among expatriate HCWs and to vaccinate non-immune individuals before they start working. ${ }^{10-12}$ According to our knowledge, there are no previous studies on the prevalence of IgG against VZV and RV among expatriate HCWs coming to work in Kuwait. The aim of this study was to assess the overall seroprevalence of IgG against VZV and RV among expatriate HCWs recruited to work in Kuwait, and to determine the between-group differences in the prevalence of seronegativity by nationality, gender, age group and occupation.

\section{Objectives}

To assess the overall state of immunity to VZV and RV among newly recruited HCWs in Kuwait before they started working, and to determine the differences in the prevalence of seronegativity between different nationalities, genders, age groups and occupation groups.

\section{METHODS}

This cross-sectional study was conducted from April 2015 to January 2016. Informed verbal consent was obtained from the HCWs prior to their inclusion, and all agreed to participate in the study. The informed consent process followed WHO Research Ethics Review Committee criteria for obtaining informed consent. ${ }^{13}$

The study included 1540 non national HCWs who constitute all the non- national HCWs recruited during the study period. They were interviewed during the study period at the Kuwaiti Expatriate Examination Centre during their compulsory blood collection and examination as prerequisite for residency approval. The interviews involved a short list of questions on sociodemographic characteristics (age, gender, country of origin and occupation). Routine blood samples were collected from each HCW as a prerequisite for obtaining official residency in Kuwait. The samples collected were transferred to the Central Virology Laboratory, which is accredited by the WHO. For each sample, serum was separated using a centrifuge and stored at $-20^{\circ} \mathrm{C}$ prior to testing.

Enzyme-linked immunoassays (EIAs) for VZV-specific and RV-specific IgG were performed using Roche Diagnostics Kits. The EIAs had a sensitivity of $100 \%$ and a specificity of $88 \%$. As part of the testing process, optical density (OD) values were obtained according to the manufacturer's instructions. Each sample was classified as negative if the OD was $<0.20$ and positive if it was $>0.70$; sera with equivocal OD values between 0.20 and 0.70 were also considered negative.

Data were analysed using SPSS V.20 software. After conducting descriptive statistical analyses, we used $\chi^{2}$ test and $\chi^{2}$ with Fisher's exact (when applicable) test to assess the between-group differences in the prevalence of seronegativity for the four categorical variables: nationality (Indian, Egyptian, Filipino, Somali and other), gender, age $(<20,20-30,30-40$ and $\geq 40$ years) and occupation (physician, nursing staff (ie, nurse or nursing assistant), technician and others). $\mathrm{P}$ values $<0.05$ were considered statistically significant.

\section{RESULTS}

The results showed that $279(18.1 \%)$ of the HCWs were seronegative for VZV. Tables 1 and 2 show the betweengroup differences in the prevalence of VZV seronegativity by nationality, gender, age group and occupation, respectively. The seronegative rate was highest among Indians $(23.5 \%)$, followed by Somalis (12.5\%), Filipinos $(6.5 \%)$ and finally Egyptians (5.4\%). Using Indian as the reference category, the differences with the Egyptian, Filipino and other groups were all significant $(\mathrm{p}<0.001)$; however, the difference with the Somali group was not. Analysis by gender demonstrated that seronegativity was more prevalent among male $(22.2 \%)$ than female (15.6\%) HCWs, and the difference was significant $(\mathrm{p}<0.001)$. Regarding age groups, the 20-30 and 30-40years old were most likely to be seronegative, with rates of $18.2 \%$ and $18.9 \%$, 
Table 1 Varicella zoster virus-specific IgG seroprevalence among HCWs according to sociodemographic criteria

\begin{tabular}{|c|c|c|c|c|}
\hline & \multirow[b]{2}{*}{$\begin{array}{l}\text { Total, } \\
\text { N (\%) }\end{array}$} & \multicolumn{2}{|c|}{ IgG serological result } & \multirow[b]{2}{*}{ P values } \\
\hline & & $\begin{array}{l}\text { Positive, } \\
\text { n (\%) }\end{array}$ & $\begin{array}{l}\text { Negative, } \\
\text { n (\%) }\end{array}$ & \\
\hline \multicolumn{5}{|l|}{ Nationality } \\
\hline Indian* & $1081(70.2)$ & 827 (76.5) & $254(23.5)$ & \\
\hline Egyptian & $274(17.8)$ & 259 (94.5) & $15(5.5)$ & $<0.001$ \\
\hline Filipino & $44(2.8)$ & $41(93.2)$ & $3(6.8)$ & $<0.001 \dagger$ \\
\hline Somali & $16(1.1)$ & $14(87.5)$ & $2(12.5)$ & $>0.05 \dagger$ \\
\hline Other & $125(8.1)$ & $120(96)$ & $5(4)$ & $<0.001 \dagger$ \\
\hline \multicolumn{5}{|l|}{ Gender } \\
\hline Female & $960(62.3)$ & $810(84.4)$ & $150(15.6)$ & $<0.001$ \\
\hline Male & $580(37.7)$ & $451(77.8)$ & $129(22.2)$ & \\
\hline \multicolumn{5}{|l|}{ Age in years } \\
\hline$<20^{*}$ & $40(2.6)$ & $35(87.5)$ & $5(12.5)$ & \\
\hline 20-30 & $674(43.8)$ & $551(81.8)$ & $123(18.2)$ & $>0.05$ \\
\hline $30-40$ & $644(41.8)$ & $522(81.1)$ & 122 (18.9) & $>0.05$ \\
\hline$\geq 40$ & $182(11.8)$ & $153(74.1)$ & $29(15.9)$ & $>0.05$ \\
\hline Total & $1540(100)$ & 1261 (81.9) & $279(18.1)$ & \\
\hline
\end{tabular}

*Reference category.

$\dagger$ Fisher's exact $\chi^{2}$ test.

HCWs, healthcare workers.

respectively; however, there were no significant differences compared with those aged $<20$ years. VZV seronegativity was most common among nurses $(21.1 \%)$ and least common among physicians $(9.2 \%)$, and the difference was significant. The prevalences among technicians and other HCWs were $15.7 \%$ and $17.7 \%$, respectively, and the difference (compared with physicians) was significant for technicians but not for other occupations.

Only $100(6.5 \%)$ of the HCWs were seronegative for RV. Tables 3 and 4 show the between-group differences in the prevalence of RV seronegativity by nationality, gender, age group and occupation, respectively. The percentage of seronegative individuals was highest among Somalis $(12.5 \%)$ and lowest among Indians (5.3\%). The percentage for other nationalities (Egyptian, Filipino and

Table 2 Varicella zoster virus-specific IgG seroprevalence among HCWs by occupation

\begin{tabular}{|c|c|c|c|c|}
\hline \multirow[b]{2}{*}{ Occupation } & \multirow[b]{2}{*}{$\begin{array}{l}\text { Total, } \\
\text { N (\%) }\end{array}$} & \multicolumn{2}{|c|}{ IgG serological result } & \multirow[b]{2}{*}{ P values } \\
\hline & & $\begin{array}{l}\text { Positive, } \\
\text { n (\%) }\end{array}$ & $\begin{array}{l}\text { Negative, } \\
\mathrm{n}(\%)\end{array}$ & \\
\hline Physician* & $174(11.3)$ & $158(90.8)$ & $16(9.2)$ & \\
\hline Nursing staff & $792(51.4)$ & 625 (79.9) & $167(21.1)$ & $<0.001$ \\
\hline Technician & $286(18.6)$ & $241(74.3)$ & $45(15.7)$ & $<0.05$ \\
\hline Other & $288(18.7)$ & 237 (82.3) & $51(17.7)$ & $>0.05$ \\
\hline Total & $1540(100)$ & 1261 (81.9) & $279(18.1)$ & \\
\hline
\end{tabular}

${ }^{*}$ Reference category.

HCWs, healthcare workers.
Table 3 Rubella virus-specific lgG seroprevalence among HCWs by some sociodemographic criteria

\begin{tabular}{|c|c|c|c|c|}
\hline & \multirow[b]{2}{*}{$\begin{array}{l}\text { Total, } \\
\text { N (\%) }\end{array}$} & \multicolumn{2}{|c|}{ IgG serological result } & \multirow[b]{2}{*}{$P$ values } \\
\hline & & $\begin{array}{l}\text { Positive, } \\
\text { n (\%) }\end{array}$ & $\begin{array}{l}\text { Negative, } \\
\text { n (\%) }\end{array}$ & \\
\hline \multicolumn{5}{|l|}{ Nationality } \\
\hline Indian* & 1081 (70.2) & $1024(94.7)$ & $57(5.3)$ & \\
\hline Egyptian & $274(17.8)$ & 249 (90.9) & $25(9.1)$ & $<0.05$ \\
\hline Filipino & $44(2.8)$ & $40(90.9)$ & $4(9.1)$ & $>0.05 \dagger$ \\
\hline Somali & $16(1.1)$ & $14(87.5)$ & $2(12.5)$ & $>0.05 \dagger$ \\
\hline Other & $125(8.1)$ & $113(90.4)$ & $12(9.6)$ & $>0.05$ \\
\hline \multicolumn{5}{|l|}{ Gender } \\
\hline Female & $960(62.3)$ & $903(94.1)$ & $57(5.9)$ & $>0.05$ \\
\hline Male & $580(37.7)$ & 537 (92.6) & $43(7.4)$ & \\
\hline \multicolumn{5}{|l|}{ Age in years } \\
\hline$<20^{*}$ & $40(2.6)$ & $33(82.5)$ & $7(17.5)$ & \\
\hline $20-30$ & $674(43.8)$ & $635(94.2)$ & $39(5.8)$ & $<0.001$ \\
\hline $30-40$ & $644(41.8)$ & $609(94.6)$ & $35(5.4)$ & $<0.001$ \\
\hline$\geq 40$ & $182(11.8)$ & $163(89.6)$ & $19(10.4)$ & $>0.05$ \\
\hline Total & $1540(100)$ & $1440(93.5)$ & $100(6.5)$ & \\
\hline
\end{tabular}

${ }^{\star}$ Reference category.

†Fisher's exact $\chi^{2}$ test.

HCWs, healthcare workers.

others) ranged between $9.1 \%$ and $9.6 \%$. Using Indian as the reference category, there was a significant difference with Egyptians $(p<0.05)$; however, the differences with the Filipino, Somali and other groups were not significant. Analysis by gender showed that a higher proportion of male $(7.4 \%)$ than female $(5.9 \%)$ HCWs were seronegative; however, the difference was not significant. Regarding age groups, the seronegativity rate was highest for the youngest group ( $<20$ years old) $(17.5 \%)$, followed by the oldest group ( $\geq 40$ years old) $(10.4 \%)$. The rates for the age groups of $20-30$ and $30-40$ years old were $5.8 \%$ and $5.4 \%$, respectively, and the differences (compared with those aged $<20$ years) were significant. RV seronegativity was highest among nurses $(6.9 \%)$ and lowest

Table 4 Rubella virus-specific IgG seroprevalence among HCWs by occupation

\begin{tabular}{|c|c|c|c|c|}
\hline \multirow[b]{2}{*}{ Occupation } & \multirow[b]{2}{*}{$\begin{array}{l}\text { Total, } \\
\text { N (\%) }\end{array}$} & \multicolumn{2}{|c|}{ IgG serological result } & \multirow[b]{2}{*}{$P$ values } \\
\hline & & $\begin{array}{l}\text { Positive, } \\
\text { n (\%) }\end{array}$ & $\begin{array}{l}\text { Negative, } \\
\text { n (\%) }\end{array}$ & \\
\hline Physician* & $174(11.3)$ & $165(94.8)$ & $9(5.2)$ & \\
\hline Nursing staff & $792(51.4)$ & $737(93.1)$ & $55(6.9)$ & $>0.05$ \\
\hline Technician & $286(18.6)$ & $268(93.7)$ & $18(6.3)$ & $>0.05$ \\
\hline Other & $288(18.7)$ & $270(93.7)$ & $18(6.3)$ & $>0.05$ \\
\hline Total & $1540(100)$ & $1440(93.5)$ & $100(6.5)$ & \\
\hline
\end{tabular}

${ }^{*}$ Reference category.

HCWs, healthcare workers. 
among physicians (5.2\%); however, the difference was not significant.

\section{DISCUSSION}

In this study, we aimed to assess the overall prevalence of VZV-specific and RV-specific IgG seropositivity among newly recruited expatriate HCWs in Kuwait and to assess the differences in the prevalence of seronegativity between different nationalities, genders, age groups and occupation groups. This study targeted the new recruited HCWs for the Kuwaiti healthcare system due to the fact that it is compulsory for them to be checked against VZV and RV antibodies prior their inclusion in the healthcare system. The ultimate goal is to help to prevent nosocomial infections and reduce the risk of VZV and RV transmission to high-risk groups (pregnant women, newborns immunocompromised patients and elderly individuals) to protect individuals in hospitals and in the wider community from serious sequelae that could overburden the healthcare system and community development programmes.

The study included 1540 expatriate HCWs who had been newly recruited to work in Kuwait. We found that $81.9 \%$ and $96.5 \%$ of HCWs were immune to VZV and $\mathrm{RV}$, respectively. Somewhat similar results were found in a study conducted in Saudi Arabia, where the corresponding seropositivity rates among HCWs were $86 \%$ for VZV and $90 \%$ for $\mathrm{RV} .{ }^{14}$ In Japan, the corresponding rates were $96.3 \%$ for VZV and $89.5 \%$ for $\mathrm{RV}^{15}$ In several other studies, the seropositivity rates for VZV and RV among HCWs were much more similar. For example, in an Australian study, the rates were $89.1 \%$ for VZV and $91.1 \%$ for RV, ${ }^{16}$ and in an Italian study, the rates were 97.9\% VZV and $97.6 \%$ for RV, ${ }^{17}$ and in a Turkish study, the rates were $98.0 \%$ for VZV and $98.3 \%$ for RV. ${ }^{18}$ The regional differences in seropositivity rates may be attributable to differences in early childhood immunisation programmes in each country. In addition, the differences could be due to the fact that we tested newly recruited expatriate HCWs, while the other studies tested HCWs who were already working in the healthcare systems of the study countries.

Our study revealed that more male HCWs were seronegative for VZV and RV (22.2\% and 7.4\%, respectively) compared with female HCWs $(15.6 \%$ and $5.9 \%$, respectively), although the difference in RV seronegativity was not significant. The VZV result differs to that reported in an Iranian study published in $2010,{ }^{19}$ which found that most female HCWs were seropositive for VZV. This could be explained by the fact that the majority of expatriate HCWs recruited to Kuwait were from low-income countries and these regions may not have had an immunisation programme for VZV during the relevant periods, since the VZV vaccine is expensive.

Regarding the RV seroprevalence among male and female HCWs, our result concurs with the findings of a study in Spain in $2014,{ }^{20}$ which reported no significant difference between male and female HCWs. In contrast, a
Japanese survey in $2001^{15}$ revealed that male HCWs were more likely to be RV seronegative than female HCWs, which was explained by the fact that the routine childhood $R V$ vaccination programme in Japan was started in the late 1970s and only involved girls aged 12-15years old, meaning that seropositivity would be more likely in female than male HCWs.

The prevalence of VZV seronegativity was higher among the age groups of 20-30 and 30-40years old, with rates of $18.2 \%$ and $18.9 \%$, respectively. For RV, the prevalence of seronegativity was higher among the youngest age group ( $<20$ years old) followed by eldest age group ( $>40$ years old), with rates of $71.5 \%$ and $10.4 \%$, respectively, for RV. Our VZV seronegativity rates are higher than those found in an Iranian study published in 2010, ${ }^{19}$ which reported a seronegativity rate of $31.9 \%$ in the same age group (20-40 years). VZV seronegativity rates in this age group have been reported to be lower in other countries: $3.8 \%$ in Finland in $2005,{ }^{21} 11.3 \%$ in Ireland in $2004,{ }^{22} 20 \%$ in Italy in $2007^{23}$ and $56.2 \%$ in Sri Lanka in $2000 .{ }^{24}$ However, the youngest age group ( $<20$ years old) had a greater RV seronegativity rate than all the other age groups. These results are consistent with the results of a Turkish study in 2012, ${ }^{25}$ which found a significant association between younger age group and greater seronegativity rate. Similar results were reported by other Turkish studies ${ }^{26-29}$ and an Australian investigation. ${ }^{16}$

Seronegativity was highest among nurses for both VZV $(21.1 \%)$ and $\mathrm{RV}(6.9 \%)$ and lowest among physicians $(9.2 \%$ and $5.2 \%$, respectively). These results concur with those from a Turkish study published in 2012, ${ }^{25}$ which found that physicians had the lowest seronegativity rate among the HCWs studied. This may be attributable to the fact that they are more exposed to VZV and RV infections, leading them to ensure that they receive their vaccinations as scheduled. Similar results were found in studies in Iran in $2001^{19}$ and Brazil in 2000. ${ }^{30}$ A study in Japan in $2001^{15}$ reported similar results for VZV; however, there were some differences regarding RV as they found that physicians had a lower seropositivity rate $(86.4 \%)$ than nurses $(91.2 \%)$.

Nurses constitute more than $50 \%$ of all HCWs recruited to work in Kuwait, ${ }^{31}$ and the majority of them come from India, which does not have a VZV and RV immunisation programme, leading to high rates of seronegativity. Moreover, the HCWs generally come from low-income countries $^{31}$ that lack consistent immunisation programmes for both VZV and RV, which might have caused the high seronegativity rates among the HCWs.

One of the limitations of this study is that equivocal EIA results were considered negative, and we were unable to obtain new blood samples from these HCWs for retesting.

In conclusion, our study revealed the VZV-specific and $\mathrm{RV}$-specific IgG seroprevalence among newly recruited HCWs in Kuwait. This study has important implications, as it provides estimates of the prevalence of immunity to VZV and RV among HCWs who will provide services throughout the healthcare system in Kuwait. This 
information could help in planning a VZV and RV vaccination programme for seronegative HCWs who, if not vaccinated (and converted to a seropositive status), could transmit these diseases to vulnerable groups, leading to severe complications.

This study highlights the importance of screening for IgG against both viruses in the countries of origin of the HCWs and vaccinating those that are seronegative before they come to work in Kuwait.

It is recommended that a seroprevalence survey is carried out among all HCWs (ie, all those currently working in the Kuwaiti healthcare system) to assess the prevalence of immunity among them so that an effective immunisation programme can be designed, with the ultimate goal of preventing VZV and RV infections in vulnerable groups.

Acknowledgements The author would like to express his deepest gratitude to $\mathrm{Dr}$ Sami Alnasser for his great help and support during and after the research period.

Contributors IS contributed in the conception of the research question, design of the methods, collecting and analysing data, as well as writing, reviewing and finally submitting for publication.

Funding This research received no specific grant from any funding agency in the public, commercial or not-for-profit sectors.

Competing interests None declared.

Patient consent Obtained.

Ethics approval The study was approved by the Kuwaiti ports and borders health and public health departments ethical committees after the study protocol was reviewed.

Provenance and peer review Not commissioned; externally peer reviewed.

Data sharing statement № additional data are available.

Open Access This is an Open Access article distributed in accordance with the Creative Commons Attribution Non Commercial (CC BY-NC 4.0) license, which permits others to distribute, remix, adapt, build upon this work non-commercially, and license their derivative works on different terms, provided the original work is properly cited and the use is non-commercial. See: http://creativecommons.org/ licenses/by-nc/4.0/

(C) Article author(s) (or their employer(s) unless otherwise stated in the text of the article) 2018. All rights reserved. No commercial use is permitted unless otherwise expressly granted.

\section{REFERENCES}

1. Domínguez A, Plans P, Costa J, et al. Seroprevalence of measles, rubella, and mumps antibodies in Catalonia, Spain: results of a cross-sectional study. Eur J Clin Microbiol Infect Dis 2006;25:310-7.

2. Bramley JC, Jones IG. Epidemiology of chickenpox in Scotland: 1981 to 1998. Commun Dis Public Health 2000;3:282-7.

3. Heininger U, Seward JF. Varicella. Lancet 2006;368:1365-76.

4. Cameron JC, Allan G, Johnston F, et al. Severe complications of chickenpox in hospitalised children in the UK and Ireland. Arch Dis Child 2007;92:1062-6.

5. Persson A, Bergström T, Lindh M, et al. Varicella-zoster virus CNS disease--viral load, clinical manifestations and sequels. J Clin Virol 2009;46:249-53.

6. Liese JG, Grote V, Rosenfeld E, et al. The burden of varicella complications before the introduction of routine varicella vaccination in Germany. Pediatr Infect Dis J 2008;27:119-24.

7. US Centers for Disease Control and Prevention. Rubella: make sure your child gets vaccinated. 2016 http://www.cdc.gov/features/ rubella/ (accessed Feb 2016).
8. Centers for Disease Control and Prevention. Immunization of healthcare workers: recommendation of the Advisory Committee on Immunization Practices (ACIP) and the Hospital Infection Control Practices Advisory Committee (HICPAC). Morbidity and Mortality Weekly Report. Recommendations and Reports. 2011 http://www. cdc.gov/mmwr/preview/mmwrhtml/rr6007a1.htm (accessed Feb 2016).

9. World Health Organization Regional Health Systems Observatory. Health systems profile - Kuwait. 2006 http://apps.who.int/ medicinedocs/documents/s17297e/s17297e.pdf (accessed Feb 2016).

10. World Health Organization. Eliminating measles and rubella and preventing congenital rubella. WHO European region strategic plan 2005-2010. Geneva: World Health Organization, 2005.

11. World Health Organization. Controlling rubella and preventing congenital rubella syndrome - global progress, 2009. Wkly Epidemiol $\operatorname{Rec} 2010 ; 85: 413-8$.

12. World Health Organization. Global measles and rubella. Strategic plan 2012-2020. Geneva: World Health Organization, 2012.

13. World Health Organization Research Ethics Review Committee (ERC). The process of obtaining informed consent. http://www.who. int/rpc/research_ethics/Process_seeking_IF_printing.pdf (accessed Feb 2016).

14. Almuneef MA, Memish ZA, Balkhy HH, et al. Seroprevalence survey of varicella, measles, rubella, and hepatitis $A$ and $B$ viruses in a multinational healthcare workforce in Saudi Arabia. Infect Control Hosp Epidemiol 2006;27:1178-83.

15. Kumakura S, Shibata H, Onoda K, et al. Seroprevalence survey on measles, mumps, rubella and varicella antibodies in healthcare workers in Japan: sex, age, occupational-related differences and vaccine efficacy. Epidemiol Infect 2014;142:12-19.

16. Vagholkar S, $\mathrm{Ng} \mathrm{J}$, Chan RC, et al. Healthcare workers and immunity to infectious diseases. Aust N Z J Public Health 2008;32:367-71.

17. Fedeli U, Zanetti C, Saia B. Susceptibility of healthcare workers to measles, mumps rubella and varicella. J Hosp Infect 2002;51:133-5.

18. Celikbas A, Ergonul O, Aksaray S, et al. Measles, rubella, mumps, and varicella seroprevalence among health care workers in Turkey: is prevaccination screening cost-effective? Am J Infect Control 2006;34:583-7.

19. Talebi-Taher M, Noori M, Shamshiri AR, et al. Varicella Zoster antibodies among health care workers in a university hospital, Teheran, Iran. Int J Occup Med Environ Health 2010;23:27-32.

20. Borràs $E$, Campins $M$, Esteve $M$, et al. Are healthcare workers immune to rubella? Hum Vaccin Immunother 2014;10:686-91.

21. Alanen A, Kahala K, Vahlberg T, et al. Seroprevalence, incidence of prenatal infections and reliability of maternal history of varicella zoster virus, cytomegalovirus, herpes simplex virus and parvovirus B19 infection in South-Western Finland. BJOG 2005;112:50-6.

22. Knowles SJ, Grundy K, Cahill I, et al. Susceptibility to infectious rash illness in pregnant women from diverse geographical regions. Commun Dis Public Health 2004;7:344-8.

23. Alfonsi V, Montomoli E, Manini I, et al. Susceptibility to varicella in childbearing age women, Central Italy: Is there a need for vaccinating this population group? Vaccine 2007;25:6086-8.

24. Liyanage NP, Fernando S, Malavige GN, et al. Seroprevalence of varicella zoster virus infections in Colombo district, Sri Lanka. Indian J Med Sci 2007;61:128-34.

25. Aypak $\mathrm{C}$, Bayram $\mathrm{Y}$, Eren $\mathrm{H}$, et al. Susceptibility to measles, rubella, mumps, and varicella-zoster viruses among healthcare workers. $J$ Nippon Med Sch 2012;79:453-8.

26. Trevisan A, Morandin M, Frasson C, et al. Prevalence of childhood exanthematic disease antibodies in paramedical students: need of vaccination. Vaccine 2006;24:171-6.

27. Kanbur NO, Derman O, Kutluk T. Age-specific mumps seroprevalence of an unvaccinated population of adolescents in Ankara, Turkey. Jpn J Infect Dis 2003;56:213-5.

28. Egemen A, Aksit S, Ozacar T, et al. Measles seroprevalence in Izmir with special emphasis on measles vaccination policy for Turkey. Pediatr Int 2001:43:379-84.

29. Aksit S, Egemen A, Ozacar T, et al. Rubella seroprevalence in an unvaccinated population in Izmir: recommendations for rubella vaccination in Turkey. Pediatr Infect Dis J 1999;18:577-80.

30. Dinelli MI, Moreira T, Paulino ER, et al. Immune status and risk perception of acquisition of vaccine preventable diseases among health care workers. Am J Infect Control 2009;37:858-60.

31. World Population Review. Kuwait population. 2017. http:// worldpopulationreview.com/countries/kuwait-population/ (accessed Mar 2017). 